\title{
Increasing our understanding of pigmentary disorders
}

\author{
Pearl Grimes, MD, ${ }^{\mathrm{a}}$ James J. Nordlund, MD, ${ }^{\mathrm{b}}$ Amit G. Pandya, MD, ${ }^{\mathrm{c}}$ Susan Taylor, MD, ${ }^{\mathrm{d}}$ \\ Marta Rendon, MD, ${ }^{\mathrm{e}}$ and Jean-Paul Ortonne, $\mathrm{MD}^{\mathrm{f}}$ \\ Los Angeles, California; Dayton and Mason, Obio; Dallas, Texas; \\ New York, New York; Boca Raton, Florida; and Nice, France
}

\begin{abstract}
This article focuses on developments in pigmentary disorders that extend dermatologists' understanding of the field. Areas that are reviewed include the basic biochemistry, pharmacology, and physiology of the melanocortin system; melanosome development; genetic diseases associated with pigmentary disorders; pigmentary disorders secondary to systemic disease; drug-induced hyperpigmentation; environmental exposure to chemicals; and primary disorders of hyperpigmentation such as melasma and lentigines. Basic, clinical, and epidemiological research, along with a number of clinical case reports, were included in the review. This article also reports on the new health-related quality-of-life instrument (MELASQOL) that has been developed for women with melasma. ( J Am Acad Dermatol 2006;54:S255-61.)
\end{abstract}

$\mathrm{T}$ his article reviews published work on developments in pigmentary disorders. Basic science and epidemiological and clinical research articles are reviewed in addition to a number of illustrative clinical case reports.

The article is split into 3 main sections-molecular biology, causes of dyschromias, and primary causes of hyperpigmentation-and a conclusion. Each of the main sections lists articles that were considered of particular interest by members of the Pigmentary Disorders Academy (PDA). These articles are described and PDA members' thoughts on the significance of the findings added.

\section{MOLECULAR BIOLOGY}

Articles discussed in this section include research on a number of receptors involved in skin pigmen-

From the Vitiligo \& Pigmentation Institute of Southern California, Los Angeles, and Division of Dermatology, University of California, Los Angeles ${ }^{\text {a }}$; the Division of Dermatology, Wright State University, Dayton, and Group Health Associates, Mason ${ }^{\mathrm{b}}$ Department of Dermatology, University of Texas Southwestern Medical Center, Dallasc; Department of Dermatology, Columbia University, and the Skin of Color Center, St. Luke's-Roosevelt Hospital Center, New York ${ }^{\mathrm{d}}$; Dermatology and Aesthetic Center, Boca Raton ; and the Department of Dermatology, University of Nice-Sophia Antipolis. ${ }^{f}$

Supported by Galderma International.

Disclosure: All authors are members of the Pigmentary Disorders Academy (PDA) and receive honoraria from Galderma for their work on behalf of the Academy.

Reprint requests: Pearl Grimes, MD, Vitiligo \& Pigmentation Institute, Suite 609, 321 N Larchmont, Los Angeles, CA 90004-6408.

$0190-9622 / \$ 32.00$

(C) 2006 by the American Academy of Dermatology, Inc.

doi:10.1016/j.jaad.2005.12.042

\begin{tabular}{ll|}
\multicolumn{2}{l}{ Abbreviations used: } \\
APP: & $\beta$-amyloid precursor protein \\
BLOC-1: & biogenesis of lysosome-related \\
& organelles complex 1 \\
DLQI: & Dermatology Life Quality Index \\
HCV: & hepatitis C virus \\
HPS: & Hermansky-Pudlak syndrome \\
HRQOL: & health-related quality of life \\
IM: & imatinib mesylate \\
LHS: & Laugier-Hunziker syndrome \\
LySD: & lysosomal-storage disease \\
MC1R: & melanocortin 1 receptor \\
MSH: & melanocyte-stimulating hormone \\
PDA: & Pigmentary Disorders Academy \\
PJS: & Peutz-Jeghers syndrome \\
SAPP: & soluble amino-terminal ectodomain \\
& of APP \\
UV: & ultraviolet
\end{tabular}

tation, including the melanocortin 1 receptor (MC1R) and the $\beta$-endorphin $/ \mu$-opiate receptor, and on the development of skin pigmentation.

A review of the basic biochemistry, pharmacology, and physiology of the melanocortin system has recently been published. ${ }^{1}$ The melanocortin system consists of melanocortin peptides $(\alpha-, \beta$ - and $\gamma$ melanocyte-stimulating hormone $[\mathrm{MSH}]$ ) derived from the proopiomelanocortin gene, 5 melanocortin receptors, 2 endogenous antagonists (agouti and agouti-related protein), and 2 ancillary proteins (mahogany and syndecan-3). Recent pharmacological and genetic studies have confirmed the role of melanocortins in pigmentation, inflammation, energy homeostasis, and sexual function. Development of selective agonists and antagonists is expected to assist research on these complex physiological functions and provide an experimental 


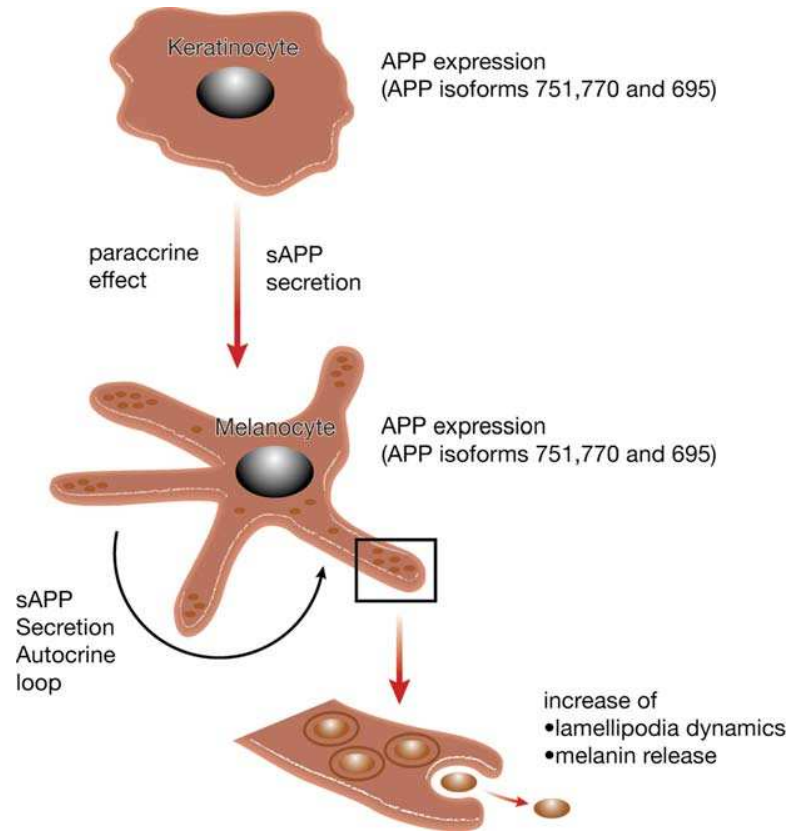

Fig 1. Expression of $\beta$-amyloid precursor protein (APP) and secretion of its soluble amino-terminal ectodomain $(S A P P)$ including its physiological effects. (Reproduced from Quast T, Wehner S, Kirfel G, Jaeger K, de Luca M, Herzog V. sAPP as a regulator of dendrite motility and melanin release in epidermal melanocytes and melanoma cells. FASEB J 2003;17:1739-41 with permission of the FASEB.)

basis for new pharmacotherapies. Scott, Suzuki, and Abdel-Malek ${ }^{2}$ assessed this further in their in vitro study on the regulation of human MC1R using normal human melanocytes from neonatal foreskins. The study reported that MC1R is regulated by paracrine factors, such as $\alpha$-MSH and agouti signaling protein, by specific endocrine sex hormones and by ultraviolet (UV) radiation. $\alpha$-MSH has been shown to up-regulate expression of MC1R, whereas agouti signaling protein has the opposite effect. Differences in the responses of normal human melanocytes in vitro to some of these factors suggest differential regulation of $M C 1 R$ gene expression, which may contribute to the variation in constitutive and UVinduced cutaneous pigmentation in humans.

Although there is no direct evidence of an interaction between melanotropin peptides and opioid receptors or between opioid peptides and melanocortin receptors, scientific evidence suggests the possibility. In a study from Han et al, ${ }^{3} 19 \alpha$-melanotropin analogues were designed from the $\delta$-opioid receptor antagonist deltorphin-II. These molecules were designed by a hybrid approach, which incorporated the hydrophobic tail and the address sequence of deltorphin-II (Glu-Val-Val-Gly- $\mathrm{NH}_{2}$ ) and key pharmacophore elements of melanotropins. After assaying for agonist activity for the MC1R from Xenopus frog skin, selected potent analogues were subsequently examined against recombinant human MC1, MC3, and MC4 receptors expressed in human embryonic kidney cells. The potent MC1R antagonist was also found to have a high affinity for the MC3R but low affinity for the MC4R. The significance of the activity of MC3R and MC4R is currently not understood. It is hoped that the development of specific agonists and antagonists for these receptors will shed light in this area. The techniques used have allowed the development of the first potent MC1R antagonist, and it is hoped that by using the same techniques more selective and potent agonists and antagonists of different human melanocortin receptors can be developed.

In a study by Berson et $\mathrm{al}^{4}{ }^{4}$ the authors assessed mechanisms involved in the production of melanosomes. It was demonstrated that cleavage of the proprotein convertase enzyme is required for melanogenesis to be initiated. Melanosomes and their precursors are lysosome-related organelles that have intraluminal fibrous striations upon which melanins are polymerized. The formation of intraluminal fibrils requires cleavage of Pmel17 by a furin-like proprotein convertase. Pmel17 itself is a type 1 integral membrane protein that is uniquely expressed by melanocytes and retinal pigment epithelial cells. Proper cleavage of Pmel17 generates a luminal domain fragment that is incorporated into the fibrils. In the absence of proprotein convertase activity, longer Pmel17 fragments are created and these are unable to form organized fibrils.

Quast et $\mathrm{al}^{5}$ described the role of $\beta$ amyloid precursor protein (APP) isoforms in melanogenesis, where they are thought to regulate dendrite motility and melanin release (Fig 1). The mode of action of its soluble amino-terminal ectodomain (SAPP) in the epidermis is comparable to other growth factors in the epidermalmelanin unit, paracrine when sAPP is derived from keratinocytes and autocrine if released by melanocytes.

Inoue et $\mathrm{al}^{6}$ studied the induction of hyperpigmentation. Some hormones or prohormones, including adrenocorticotropic hormone and $\mathrm{MSH}$, are overexpressed at times of stress. Both hormones play important roles in pigmentation. Increased numbers of dopa-positive melanocytes were found in stressed mice subjected to UV irradiation. Pretreatment with an inhibitor of adrenocorticotropic hormone, however, led to a reduction in the numbers of dopa-positive melanocytes (and thus the stress pigmentary response).

The role of neuropeptides in the control of skin color was demonstrated in an article by Kauser et al. ${ }^{7}$ They demonstrated that both the $\beta$-endorphin and $\mu$-opiate receptors are expressed in epidermal 
Table I. Classification of depigmenting agents according to mode of action*

\begin{tabular}{|c|c|c|}
\hline \multicolumn{2}{|c|}{ Stage of melanin synthesis/deposition } & Compounds \\
\hline \multirow[t]{2}{*}{ Before melanin synthesis } & Tyrosinase transcription & $\mathrm{C}_{2}$-ceramide, tretinoin \\
\hline & Tyrosinase glycosylation & $\mathrm{PaSSO}_{3} \mathrm{Ca}$ \\
\hline \multirow[t]{11}{*}{ During melanin synthesis } & Tyrosinase inhibition & Hydroquinone, 4-hydroxy-anisole \\
\hline & & 4-S-CAP and derivatives, arbutin \\
\hline & & Aloesin, azelaic acid \\
\hline & & Kojic acid, methyl gentisate \\
\hline & & Ellagic acid, resveratrol \\
\hline & & Oxyresveratrol \\
\hline & Peroxidase inhibition & Methimazole, phenols/catechols \\
\hline & Product reduction and ROS & Ascorbic acid, ascorbic acid palmitate \\
\hline & scavengers & \\
\hline & & VC-PMG, thioctic acid \\
\hline & & $\alpha$-TOC, dl- $\alpha$-TF, hydrocumarins \\
\hline \multirow[t]{7}{*}{ After melanin synthesis } & Tyrosinase degradation & Linoleic acid, $\alpha$-linoleic acid \\
\hline & Inhibition of melanosomes transfer & $\begin{array}{l}\text { Serine protease inhibitors, lecithins } \\
\text { and neoglycoproteins }\end{array}$ \\
\hline & & Soybean milk extracts, niacinamide \\
\hline & & RW-50353 \\
\hline & Skin turnover acceleration & Lactic acid, glycolic acid \\
\hline & & Liquiritin, retinoic acid \\
\hline & & Linoleic acid \\
\hline
\end{tabular}

$\alpha$-TF, $\alpha$-Tocopherol ferulate; $\alpha$-TOC, $\alpha$-tocopherol; $\mathrm{PaSSO}_{3} \mathrm{Ca}$, calcium d-pantetheine-S-sulfonate; ROS, reactive oxygen species; 4-S-CAP, 4-S-cystaminylphenol; VC-PMG, magnesium-L-ascorbyl-2-phosphate.

*Adapted from Briganti S, Camera E, Picardo M. Pigment Cell Res 2003;16:101-10.

melanocytes. The team used a cultured melanocyte system to show that $\beta$-endorphin has potent melanogenic, mitogenic, and dendritogenic effects. The $\beta$-endorphin/ $\mu$-opiate receptor system is likely to become an important area of research in the future because it offers potential for developing therapeutic agents to interact with these neuropeptides.

An interesting publication by Briganti, Camera, and Picardo ${ }^{8}$ listed the various stages of melanin production that can be interrupted to produce depigmentation and the possible agents that can act at the different steps (Table I). The evidence for the effectiveness of these therapies ranges from in vitro studies through to clinical trials.

Bovine retinas exposed to blue/green light at 390 to $520 \mathrm{~nm}$ produced quantities of hydrogen peroxide associated with a marked decrease in the amount of melanin present in the retinal pigment epithelium. ${ }^{9}$ It has been shown that oxidation of melanin and its irreversible bleaching occurs after aerobic irradiation of melanin with UV or visible light because of the formation of superoxide anion or hydrogen peroxide. The observation may have implications for treating dermal melanosis.

\section{CAUSES OF DYSCHROMIAS}

Dyschromias can be linked with a variety of causal factors-genetic predisposition, contact with various agents in the environment, as a sequel to chronic disease, or as a result of drugs prescribed for an existing condition.

\section{Genetic disorders}

Kanitakis et $\mathrm{al}^{10}$ provided a pathophysiological basis for the understanding of the development of pigmentary lesions in chromosome-linked focal dermal hypoplasia. They described a 19-year-old woman with atrophic lesions with adipocytic herniation through the dermis, papillomatous lesions, and bone anomalies. Biopsy results of the hyperpigmented lesions showed higher melanin levels in the basal layer and large dermal macrophages. Unusually, the hyperpigmentation presented as multiple lentigo-like macules at the periphery of atrophic areas. These macules first appeared at puberty and developed progressively during adolescence. The authors noted that the melanocyte stimulation within typical atrophic lesions supports the hypothesis that focal dermal hypoplasia lesions may be progressive.

Ochiai et $\mathrm{al}^{11}$ focused on the association between extrasacral mongolian spots and Hunter's syndrome. Ultrastructural findings were similar to those seen in aberrant or persistent mongolian spots or nevus of Ota, both of which persist lifelong and suggest the long-lasting nature of the hyperpigmentation. These findings are relevant for the early diagnosis of a mild 
Table II. Laugier-Hunziker syndrome: An important differential diagnosis for Peutz-Jeghers syndrome*

\begin{tabular}{|c|c|c|}
\hline & Peutz-Jeghers syndrome & Laugier-Hunziker syndrome \\
\hline Inheritance & Autosomal dominant & Sporadic \\
\hline Age at onset & Infancy or early childhood & Early to mid-life \\
\hline Cutaneous lesions & Oral and labial pigmentation & $\begin{array}{l}\text { Oral, labial, and fingertip } \\
\text { pigmentation; longitudinal } \\
\text { melanonychia }\end{array}$ \\
\hline Pigmented mucosal lesions & Lips, oral mucosa & $\begin{array}{l}\text { Buccal mucosa, lower lips, } \\
\text { hard and soft palate }\end{array}$ \\
\hline $\begin{array}{l}\text { Germline mutations on } \\
\text { chromosome } 19 \mathrm{p} 13.3\end{array}$ & $\begin{array}{l}\text { May be present in } 40 \%-60 \% \text { of } \\
\text { patients with condition }\end{array}$ & None identified \\
\hline Gl abnormalities & $\begin{array}{l}\text { Hamartomatous Gl polyposis, } \\
\text { Gl cancer }\end{array}$ & None \\
\hline Surveillance recommendations & $\begin{array}{l}\text { Upper and lower Gl endoscopy } \\
\text { with small bowel follow-up } \\
\text { every two years, early breast } \\
\text { screening every five years. } \\
\text { Gynecological exams every } 3 \text { y }\end{array}$ & None \\
\hline
\end{tabular}

Gl, Gastrointestinal.

*Based on Wirtzfeld DA, Petrelli NJ, Rodriguez-Bigas MA. Ann Surg Oncol 2001;8:319-27 ${ }^{12}$; Scott RJ, Crooks R, Meldrum CJ, Thomas L, Smith CKA, Mowat D, et al. Clin Genet 2002;62:282-7 ${ }^{13}$; Lampe AK, Hampton PJ, Woodford-Richens K, Tomlinson I, Lawrence CM, Douglas FS. J Med Genet 2003;40:e77. ${ }^{14}$

form of Hunter's syndrome in order to improve the patient's prognosis.

Table II ${ }^{12,13}$ highlights the differences between Laugier-Hunziker syndrome (LHS) and Peutz-Jeghers syndrome (PJS). LHS is an important differential diagnosis for PJS. Although there are common dermatological features within the two syndromes, PJS is associated with hamartomatous gastrointestinal polyposis and any risk of malignancy can be assessed by regular surveillance. In contrast, LHS is a benign disease with no systemic manifestations requiring no interventions. ${ }^{14}$

Widespread dermal melanocytosis as a marker for lysosomal-storage disease (LySD) was reported in a case study of two infants presenting with extensive blue cutaneous patches in the posterior and anterior trunk region. ${ }^{15}$ The article also included a literature review of widespread dermal melanocytosis with associated LySD that identified 46 patients, 24 (52\%) of which had Hurler syndrome. GM1 gangliosidosis, Niemann-Pick disease, Hunter syndrome, and $\alpha$ mannosidosis are also featured in the list. Dermal melanocytosis occurred more commonly in darker skinned infants. ${ }^{15}$

Hermansky-Pudlak syndrome (HPS) is a group of genetic diseases resulting from abnormal movement of vesicles to and among subcellular organelles, including melanosomes, platelet-dense granules, and lysosomes. At the time of the review, 4 genetic variants of HPS were known to exist (HPS-1, HPS-2, HPS-3, and HPS-4). All are associated with bleeding diathesis from abnormal platelets. Huizing, Boissy, and $\mathrm{Gahl}^{16}$ reviewed the roles played by the genes responsible for HPS, which are key to understanding protein formation and transport in people with the syndrome. Subsequently, 3 more genetic subtypes of HPS have been identified; HPS-5, HPS- 6 , and HPS-7. ${ }^{17}$ Discovery of the HPS-7 variant is of particular interest as it provides the first evidence that a mutation affecting a biogenesis of lysosome-related organelles complex 1 (BLOC-1) component causes HPS in humans. ${ }^{18}$ HPS-associated genes participate in at least 4 distinct protein complexes: the adaptor complex AP-3; BLOC-1, consisting of 4 HPS proteins (pallidin, muted, cappuccino, HPS7/sandy); BLOC2, consisting of HPS6/ruby-eye, HPS5/ruby-eye-2, and HPS3/cocoa; and BLOC-3, consisting of HPS1/ pale ear and HPS4/light ear. ${ }^{19}$

\section{Systemic disease}

Hyperpigmentation is commonly found in patients with chronic renal failure and is also one of the most evident features of porphyria cutanea tarda. Hepatitis $\mathrm{C}$ virus (HCV) is an important precipitating agent of this disease, which has been described in patients undergoing hemodialysis. A study of 47 patients undergoing hemodialysis divided patients into two groups: group 1 , anti-HCV positives $(n=17)$, and group 2, anti-HCV negatives $(\mathrm{n}=30)$. Ten patients in group 1 and 7 in group 2 developed hyperpigmentation $(P<.05){ }^{20}$ The authors concluded that dialysis patients with HCV and chronic renal failure were more likely to exhibit hyperpigmentation. 
An article discussing vitamin $\mathrm{B}_{12}$ deficiency described a 54-year-old man who had distinct hyperpigmentation of the hands, feet, and tongue along with shortness of breath and weakness. ${ }^{21} \mathrm{He}$ had a medical history that included diabetes, alcohol abuse, liver disease, and vitamin $\mathrm{B}_{12}$ deficiency secondary to malnutrition. The exact mechanism of hyperpigmentation is unknown, but a number of hypotheses have previously been put forward. A deficiency in vitamin $\mathrm{B}_{12}$ might cause a decrease in intracellular-reduced glutathione. This results in an increase in tyrosinase activity and allows an increase in melanogenesis, resulting in clinical hyperpigmentation. A decrease in hyperpigmentation usually occurs within 2 weeks of starting vitamin $\mathrm{B}_{12}$ treatment.

High and Costner ${ }^{22}$ reported the case of a 12year-old girl who presented with forehead, glabellar, preauricular, and periotic hyperpigmentation; telangiectases; and atrophic scars. The patient had been diagnosed in infancy with neonatal lupus erythematosus-an autoimmune disease with a distinctive cutaneous appearance. The condition is usually selflimiting, as the causative antibodies are maternally derived. Chronic cutaneous sequelae, as in this case, are rare. The areas of hyperpigmentation were successfully treated with hydroquinone $(4 \%)$ and tretinoin $(0.025 \%)$.

\section{Environmental chemical exposure}

In a study of the effects of consuming arseniccontaminated water, 7683 persons from India were assessed for skin disease. ${ }^{23}$ Two hundred forty-eight (3.2\%) showed clinical characteristics of arsenicosis, including raindrop (spotty) pigmentation/depigmentation of the body and extremities $(94.35 \%$ of sufferers) and keratoses of the hand (65.3\%). Pigmented abnormalities were observed in more than $80 \%$ of persons who drank water containing more than 50 $\mu \mathrm{g} / \mathrm{L}$ of arsenic. The study also reported that arsenic levels in the water were very high $(3.4 \mathrm{mg} / \mathrm{L})$.

\section{Drug-induced skin disease}

Mahé et $\mathrm{al}^{24}$ surveyed a total of 599 Senegalese women presenting with a variety of skin diseases, including dermatophyte infections $(n=105)$, scabies $(n=69)$, acne $(n=42)$, and dyschromias $(n=26)$. Seventy-one percent of these women ( 425 patients) used bleaching agents. Ninety-two percent of these applied the products to their whole body at least once a day. The cost of the products accounted for approximately $7 \%$ of their monthly income. Most were hydroquinone-based compounds (89\%), followed by corticosteroid (70\%), mercury salts (10\%), and caustic agents (17\%). They concluded that at least $55 \%$ of the diseases prompting a visit to the clinic could be classified as complications of using cosmetic bleaching agents. They suggested that the extensive use of topical steroids was responsible for conditions such as scabies and acne. Eczema, irritant dermatitis, and a lupus-like facial eruption were associated with hydroquinone use.

Tosti et $\mathrm{al}^{25}$ reported a lentiginous eruption following treatment with topical squaric acid dibutylester $(0.001 \%-0.1 \%)$ in a 16-year-old boy with alopecia universalis on the scalp and eyebrows. The hair regrew after 9 months, but subsequent relapses were treated similarly over the next 26 months. A lentiginous eruption developed around the treated areas 3 years after the first treatment and the hyperpigmented macules resembled those of psoralen-UVA-induced lentigines, although this treatment or exposure to sunlamps or excessive sunlight had not occurred. The authors suggest that possible mechanisms could be antigenic competition, nonspecific systemic suppression of delayed-type hypersensitivity, and interference with postinflammatory cytokine activity.

Bellet et $\mathrm{al}^{26}$ described a 20-year-old white woman diagnosed with Diamond-Blackfan anemia at 2 months of age. She had been receiving monthly exchange transfusions which had resulted in iron overload. Stem cell factor was used to reduce the number of transfusions required, which has a direct stimulatory effect on melanocytes and promotes mast cell hyperplasia. As a result she suffered extensive hyperpigmentation at the many injection sites, including the buttocks.

Two studies showing contrasting effects of tyrosine kinase inhibition on gray hair were reviewed. ${ }^{27,28}$ Imatinib mesylate (IM) (Gleevec) is a tyrosine kinase inhibitor that targets the BCR-ABL protein in chronic myelogenous leukemia, c-Kit, and platelet-derived growth factor receptors. Etienne, Cony-Makhoul, and Mahon ${ }^{27}$ studied 133 patients with chronic myeloid leukemia to see how IM therapy affected hair color. Nine patients had gray hair before treatment and hair repigmentation occurred after a median of 5 months of treatment. The authors of the report offered no explanation for the effects seen. By contrast, Robert et $\mathrm{al}^{28}$ found that 18 of their 28 patients being treated for chronic myelocytic leukemia with SU11428-which also blocks the receptors for vascular endothelial growth factor, platelet-derived growth factor, and stem cell factordeveloped gray hair. They suggested that the repigmentation effect seen in the first study could be related to $\mathrm{c}$-Kit; IM is known to inhibit c-Kit, a tyrosine kinase receptor. Blocking of various combinations of 3 tyrosine kinase receptors can result in very different effects on hair pigmentation. 


\section{PRIMARY DISORDERS OF HYPERPIGMENTATION Melasma}

Sarker, Jain, and Puri ${ }^{29}$ reported a review of 120 Indian melasma patients. Thirty-one (26\%) were male, which is greater than that usually reported in melasma studies. Among these, malar melasma was observed in 16 (52\%)—higher than is generally found in females. Etiology involved sunlight (45\%), family history (perhaps surprisingly low at 16\%), and exposure to phenytoin $(6 \%)$. The authors noted that the prevalence of melasma in the men could be linked to greater exposure to the sun, more cosmetic awareness, and the use of mustard seed oil as a moisturizer. Larger studies are called for to confirm this finding.

The MELASQOL scale is a new 10-item qualityof-life instrument for melasma patients. ${ }^{30}$ It was derived from existing health-related quality-of-life (HRQOL) assessments, and validation tests found the MELASQOL to be well correlated with the Dermatology Life Quality Index (DQLI) and Skindex index in terms of psychometric properties and with other HRQOL measures. The new instrument highlights the 3 life domains considered by patients to be most affected by melasma-social life, recreational and leisure life, and emotional well-being.

Balkrishnan et a $1^{30}$ randomly sampled 102 women, aged 18 to 65 years, identified as having melasma. These women were evaluated using the Melasma Area and Severity Index and then asked to complete the DLQI, the Skindex-16, a 7-point skin discoloration questionnaire, and the Fear of Negative Evaluation Questionnaire. The women were also asked to rate their perceived quality of life in 8 aspects of their lives (emotional well-being, family relationships, money matters, physical health, recreation and leisure activities, sexual relationships, social life, and work) first with melasma and then without melasma, so that an assessment of the patient's increased quality-of-life perceptions could be made. All of these data were utilized in the selection of the items to make up the MELASQOL. The 10 items chosen include 7 from Skindex-16 and 3 from the skin discoloration questionnaire, which was created for study purposes using a focus group of melasma experts. Patients are asked to rate how they feel about the following items on a scale of 1 (not bothered) to 7 (bothered all the time):

1. The appearance of your skin condition

2. Frustration about your skin condition

3. Embarrassment about your skin condition

4. Feeling depressed about your skin condition

5. The effects of your skin condition on your interactions with family, friends, close relationships, etc
6. The effects of your skin condition on your desire to be with people

7. Your skin condition making it hard to show affection

8. Skin discoloration making you feel unattractive to others

9. Skin discoloration making you feel less vital or productive

10. Skin discoloration affecting your sense of freedom

The MELASQUOL's discriminatory power is similar to that of Skindex 16 and DLQI for melasma.

\section{Absent lentigines}

The development of lentigines within psoriatic plaques is a known clinical phenomenon, but the reverse was described in a paper by Mendonça, Holmes, and Burden. ${ }^{31}$ They described a 44-year-old woman with a 10-year history of psoriasis. She sunbathed regularly and had developed multiple solar lentigines around the psoriatic plaques but not in the lesions themselves. Before this examination she had been treated with topical therapies and one course of narrowband UVB therapy. Histology of a lentigo adjacent to a psoriatic plaque revealed an increase in basal melanocytes and basal hyperpigmentation. The psoriasis was cleared with dithranol and this area remained free of lentigines 2 months later. A 10-year-old white boy had had psoriasis with multiple lentigines outside the psoriatic plaques since the age of 3 years. ${ }^{31}$ The psoriasis was successfully treated with coal tar and at 3 months after treatment, the areas remained free of psoriasis and lentigines. It is believed that there could be some $\mathrm{T}$ helper cell type 1 cytokines in psoriatic lesions, which can inhibit melanin production. Kang and Kang $^{32}$ reported the case of a 30-year-old Korean woman with lentigines grouped on the left side of her face without mucosal involvement, which she had had from 7 years of age. The authors suggested that the segmental nature of the lesions could be diagnosed as agminated lentigines. However, the lack of symmetry, the early age at onset, the presence of dermal melanocytes, and a lack of elongated rete ridges led them to diagnose nevus of Ota in this case.

\section{CONCLUSION}

There has been much improvement in the understanding of the mechanisms underlying pigmentary disorders. As our understanding grows, new treatment strategies are being developed and new areas of research assessed. The articles presented herein are just a snapshot of this rapidly progressing area.

Studying multiple different factors involved in the production of melanin, its transfer, its degradation, and the various inhibitors of these steps, is key 
to understanding pigmentary disorders-one can no longer think only in terms of the action of tyrosinase in pigmentation. This understanding will enable the development of novel agents that enhance or suppress the natural production of melanin.

Moreover, the epidemiological studies and case reports reviewed herein suggest causes of pigmentary changes and provide much food for thought and possible areas for further research. The importance of such studies lies not only in informing dermatologists about the more unusual dyschromias, but also in the opportunities they present to evaluate the disorder-and its treatment-in a more effective way.

Beyond the simple treatment of dyschromias, the development of a quality-of-life measure for melasma indicates that the psychological effects of some pigmentary disorders are now being recognized and measured. Understanding the effects that dyschromias have on patients' lives will help practitioners prioritize therapy, which in turn will drive the need to further understand the mechanisms underlying the disease and, thus, the development of new therapies.

\section{REFERENCES}

1. Gantz I, Fong TM. The melanocortin system. Am J Physiol Endocrinol Metab 2003;284:E468-74.

2. Scott MC, Suzuki I, Abdel-Malek ZA. Regulation of the human melanocortin 1 receptor expression in epidermal melanocytes by paracrine and endocrine factors and by ultraviolet radiation. Pigment Cell Res 2002;15:433-9.

3. Han G, Quillan JM, Carlson K, Sadée W, Hruby VJ. Design of novel chimeric melanotrophin- deltorphin analogues. Discovery of the first potent human melanocortin 1 receptor antagonist. J Med Chem 2003;46:810-9.

4. Berson JF, Theos AC, Harper DC, Tenza D, Raposo G, Marks MS. Proprotein convertase cleavage liberates a fibrillogenic fragment of a resident glycoprotein to initiate melanosome biogenesis. J Cell Biol 2003;161:521-33.

5. Quast T, Wehner S, Kirfel G, Jaeger K, de Luca M, Herzog V. sAPP as a regulator of dendrite motility and melanin release in epidermal melanocytes and melanoma cells. FASEB J 2003;17:1739-41.

6. Inoue K, Hosoi J, Ideta R, Ohta N, Ifuku O, Tsuchiya T. Stress augmented ultraviolet-irradiation-induced pigmentation. J Invest Dermatol 2003;121:165-71.

7. Kauser S, Schallreuter KU, Thody AJ, Gummer C, Tobin DJ. Regulation of human epidermal melanocyte biology by $\beta$-endorphin. J Invest Dermatol 2003;120:1073-80.

8. Briganti S, Camera E, Picardo M. Chemical and instrumental approaches to treat hyperpigmentation. Pigment Cell Res 2003; 16:101-10.

9. Sarna T, Burke JM, Korytowski W, Rózanowska M, Skumatz CMB, Zaręba A, et al. Loss of melanin from human RPE with aging: possible role of melanin photooxidation. Exp Eye Res 2003;76:89-98.

10. Kanitakis J, Souillet A-L, Butnaru C, Claudy A. Melanocyte stimulation in focal dermal hypoplasia with unusual pigmented skin lesions: a histologic and immunohistochemical study. Paediatr Dermatol 2003;20:248-52.

11. Ochiai $T$, Ito $K$, Chin $M$, Shichino $H$, Mugishima $H$. Significance of extensive Mongolian spots in Hunter's syndrome. $\mathrm{Br} \mathrm{J}$ Dermatol 2003;148:1173-8.
12. Wirtzfeld DA, Petrelli NJ, Rodriguez-Bigas MA. Hamartomatous polyposis syndromes: Molecular genetics, neoplastic risk, and surveillance recommendations. Ann Surg Oncol 2001;8:319-27.

13. Scott RJ, Crooks R, Meldrum CJ, Thomas L, Smith CJA, Mowat $D$, et al. Mutation analysis of the STK11/LKB1 gene and clinical characteristics of an Australian series of Peutz-Jeghers syndrome patients. Clin Genet 2002;62:282-7.

14. Lampe AK, Hampton PJ, Woodford-Richens K, Tomlinson I, Lawrence CM, Douglas FS. Laugier-Hunziker syndrome: an important differential diagnosis for Peutz-Jeghers syndrome. J Med Genet 2003;40:e77.

15. Hanson M, Lupski JR, Hicks J, Metry D. Association of dermal melanocytosis with lysosomal storage disease. Arch Dermatol 2003;139:916-20.

16. Huizing M, Boissy RE, Gahl WA. Hermansky-Pudlak syndrome: vesicle formation from yeast to man. Pigment Cell Res 2002; 15:405-19.

17. Zhang $\mathrm{Q}$, Zhao B, Li W, Oiso N, Novak EK, Rusiniak ME, et al. Ru2 and Ru encode mouse orthologs of the genes mutated in human Hermansky-Pudlak syndrome types 5 and 6 . Nat Genet 2003;33:145-53.

18. Li W, Zhang Q, Oiso N, Novak EK, Gautam R, O'Brienet EP, et al. Hermansky-Pudlak syndrome type 7 (HPS-7) results from mutant dysbindin, a member of the biogenesis of lysosomerelated organelles complex 1 (BLOC-1). Nat Genet 2003;35:84-9.

19. Gwynn B, Martina JA, Bonifacino JS, Sviderskaya EV, Lamoreux $M L$, Bennett $D C$, et al. Reduced pigmentation ( $r p$ ), a mouse model of Hermansky-Pudlak syndrome, encodes a novel component of the BLOC-1 complex. Blood 2004;104:3181-9.

20. Choi HK, Thome FS, Orlandini T, Barros E. Increased skin pigmentation in patients with chronic renal failure undergoing hemodialysis infected with the hepatitis $C$ virus. Rev Assoc Med Bras 2003;49:24-8.

21. Hoffman CF, Palmer DM, Papadopoulos D. Vitamin $B_{12}$ deficiency: a case report of ongoing cutaneous hyperpigmentation. Cutis 2003;71:127-30.

22. High WA, Costner MI. Persistent scarring, atrophy, and dyspigmentation in a preteen girl with neonatal lupus erythematosus. J Am Acad Dermatol 2002;48:626-8.

23. Guha Mazumdar DN. Chronic arsenic toxicity: clinical features, epidemiology, and treatment: experience in West Bengal. J Environ Sci Health Part A Tox Hazard Subst Environ Eng 2003;38:141-63.

24. Mahé A, Ly F, Aymard G, Dangou JM. Skin diseases associated with the cosmetic effects of bleaching products in women from Dakar, Senegal. Br J Dermatol 2003;148:493-500.

25. Tosti A, Piraccini BM, Misciali C, Vincenzi C. Lentiginous eruption due to topical immunotherapy. Arch Dermatol 2003;139: 544-55.

26. Bellet JS, Obadiah JM, Frothingham BM, Kurtzberg J, Grichnik JM. A patient with extensive stem cell factor-induced hyperpigmentation. Cutis 2003;71:149-62.

27. Etienne G, Cony-Makhoul P, Mahon F-X. Imatinib mesylate and gray hair. N Engl J Med 2002;347:446.

28. Robert C, Spatz A, Faivre S, Armand J-P, Raymond R. Tyrosine kinase inhibition and grey hair. Lancet 2003;361:1056.

29. Sarkar R, Jain RK, Puri P. Melasma in Indian males. Dermatol Surg 2003;29:204.

30. Balkrishnan R, McMichael AJ, Camacho FT, Saltzberg F, Housman TS, Grummer S, et al. Development and validation of a health-related quality of life instrument for women with melasma. Br J Dermatol 2003;149:572-7.

31. Mendonça CO, Holmes S, Burden AD. Absent lentigines in psoriatic plaques. Br J Dermatol 2003;147:1020.

32. Kang HY, Kang WH. Bilateral type of nevus of Ota presenting as agminated lentigines. Eur J Dermatol 2003;13:205-6. 